\title{
IMPLEMENTASI MODEL PEMBELAJARAN LEARNING TOGETHER DALAM PEMAHAMAN MANASIK HAJI SANTRI MADRASAH DINIYAH MANBA'UL HIKAM
}

\author{
Nasiri \\ STAI Taruna Surabaya \\ Email: nasiri@staitaruna.ac.id \\ Siti Hafshah Solehatunnisa \\ STAI Taruna Surabaya \\ Email: sitihs@staitaruna.ac.id
}

\begin{abstract}
The purpose of this research is: (1) Knowing the implementation of learning together learning model in understanding the 6th grade of Hajj santri ulya Madrasah Diniyah Manba'ul Hikam Tanggulangin Sidoarjo school year 2020/2021. (2) Knowing the obstacles and finding solutions in understanding the 6th class of Ulya Hajj. (3) Knowing the solution to the obstacles found in the understanding of hajj santri class 6 Ulya. This research uses qualitative description research methods, conducted at Madrasah diniyah Manba'ul Hikam Tanggulangin Sidoarjo in May 2021 - August 2021. Methods of data collection with interviews, observations, and documentation. To find out the validity of the data using trianggulation strategies and methods. Data is analyzed using interactive models with data reduction measures, data presentation, and drawing conclusions. The results showed that: (1) the implementation of the learning model of learning together is more active and has a sense of responsibility towards themselves and members. (2) The obstacle is that the debriefing or theory given is less able to understand the students, but at the time of the practice of hajj examinations take place. (3) The solution to overcome the obstacles found is that the students must really pay attention to the understanding of hajj manasik carefully so that the implementation of hajj manasik can run smoothly.
\end{abstract}

Keywords : Implementation of Learning Model, Learning Together, Understanding of Hajj Manasik

\begin{abstract}
Abstrak
Tujuan penelitian ini adalah : (1) Mengetahui implementasi model pembelajaran learning together dalam pemahaman manasik haji santri kelas 6 ulya Madrasah Diniyah Manba'ul Hikam Tanggulangin Sidoarjo tahun ajaran 2020/2021. (2) Mengetahui kendala serta menemukan solusi dalam pemahaman manasik haji santri kelas 6 Ulya. (3) Mengetahui solusi atas kendala yang ditemukan dalam pemahaman manasik haji santri kelas 6 Ulya. Penelitian ini menggunakan metode penelitian deskripsi kualitatif, dilaksanakan di Madrasah diniyah Manba'ul Hikam Tanggulangin Sidoarjo bulan Mei 2021 - Agustus 2021. Metode pengumpulan data dengan wawancara, observasi, dan dokumentasi. Untuk mengetahui keabsahan data menggunakan trianggulasi strategi dan metode. Data dianalisis menggunakan model interaktif dengan langkah-langkah reduksi data, penyajian data, dan menarik kesimpulan. Hasil penelitian menunjukkan bahwa: (1) implementasi model pembelajaran learning together lebih membuat para santri aktif dan mempunyai rasa tanggung jawab terhadap diri nya sendiri maupun anggota. (2) Adapun kendalanya ialah pembekalan atau teori yang diberikan kurang bisa memahami para santri, namun pada saat praktek ujian manasik haji berlangsung. (3) Solusi untuk mengatasi kendala yang ditemukan adalah para santri harus benar-benar memperhatikan pemahaman manasik haji dengan seksama agar pelaksanaan manasik haji bisa berjalan dengan lancar.
\end{abstract}

Kata Kunci: Implementasi Model Pembelajaran, Learning Together, Pemahaman Manasik Haji 


\section{Pendahuluan}

\section{Latar Belakang Masalah}

Pendidikan adalah usaha sadar dan terencana untuk mewujudkan suasana belajar dan proses pembelajaran untuk peserta didik secara aktif mengembangkan potensi dirinya untuk memiliki kekuatan spiritual keagamaan, pengendalian diri, kepribadian, kecerdasan, akhlak mulia, serta keterampilan yang diperlukan dirinya, masyarakat, bangsa, dan negara.

Pendidikan mengandung tujuan yang ingin dicapai, yaitu individu yang berkembang kemampuannya sehingga bermanfaat untuk kepentingan hidupnya, atau sebagai warga masyarakat maupun sebagai warga negara. ${ }^{1}$

Tujuan pendidikan memuat gambaran tentang nilai-nilai yang baik, luhur, pantas, benar, dan indah untuk kehidupan. Tujuan Pendidikan Nasional Undang-Undang Dasar nomor 20 tahun 2003 pasal 3 adalah mengembangkan kemampuan dan membentuk watak serta peradaban bangsa yang bermartabat dalam rangka mencerdaskan kehidupan bangsa, bertujuan untuk berkembangnya potensi peserta didik agar menjadi manusia yang beriman dan bertakwa kepada Tuhan Yang Maha Esa, berakhlak mulia, sehat, berilmu, cakap, kreatif, mandiri, dan menjadi warga negara yang demokratis serta bertanggung jawab.

Salah satu wadah dari pendidikan tersebut adalah sekolah, yaitu sebagai sarana pembentukan siswa secara formal yang berada pada jalur pendidikan yang terstruktur dan terprogram. Sekolah merupakan sumber pengalaman pendidikan, karena semua sekolah secara keseluruhan merupakan lingkungan pendidikan. Melalui pendidikan manusia memperoleh ilmu-ilmu yang belum diketahui sebelumnya.

Adapun beberapa pengertian pendidikan menurut beberapa tokoh, salah satunya adalah Ibnu Sina dan H. Fuad Ihsan. Menurut Ibnu Sina, pendidikan adalah proses untuk membentuk perkembangan anak dan membiasakan kebiasaan yang baik dan sifat-sifat baik menjadi faktor utama guna mencapai kebahagiaan anak. Sedangkan menurut H. Fuad Ihsan, pendidikan adalah usaha manusia untuk menumbuhkan dan mengembangkan potensipotensi pembawaan baik jasmani maupun rohani sesuai dengan nilai-nilai yang ada di dalam masyarakat dan kebudayaan.

Pendidikan sebagai salah satu sektor yang paling penting dalam pembangunan nasional, dijadikan andalan untuk berfungsi semaksimal mungkin dalam upaya meningkatkan kualitas hidup manusia Indonesia, di mana iman dan taqwa kepada Tuhan Yang Maha Esa menjadi sumber motivasi kehidupan di segala bidang. Dalam hal ini pendidikan agama bukanlah sekedar mengajarkan pengetahuan agama dan melatih keterampilan anak dalam melaksanakan 18 ibadah. Akan tetapi pendidikan agama jauh lebih luas dari pada itu, ia pertama-tama bertujuan untuk membentuk kepribadian anak sesuai dengan ajaran agama. Pembinaan sikap mental dan akhlak jauh lebih penting daripada pandai menghafal dalil-dalil dan hukum-hukum agama, yang tidak diresapkan dan dihayatinya dalam hidup. Pendidikan agama hendaknya dapat mewarnai kepribadian anak, sehingga agama itu benar-benar menjadi bagian dari kepribadiannya yang akan menjadi pengendali dalam hidupnya di kemudian hari. ${ }^{2}$

Pendidikan agama yang dimaksud adalah seperti pendidikan pesantren. Pengertian dari pesantren itu sendiri adalah suatu lembaga pendidikan tradisional Islam yang bertujuan

${ }^{1}$ Dwi Nugroho Hidayanto dkk, Pengantar Ilmu Pendidikan Teoritis Sistematis untuk Guru dan Calon Guru, (Depok: PT RajaGrafindo Persada, 2020), hlm. 2.

2 Zakiyah Daradjat, Ilmu Jiwa Agama, (Jakarta: Bulan Bintang, 1996), hlm. 107. 
untuk mempelajari, memahami, mendalami, menghayati, dan mengamalkan ajaran Islam dengan menekankan pentingnya moral keagamaan sebagai pedoman perilaku sehari-hari.

Pendidikan pesantren mempunyai lima elemen pokok yang merupakan ciri umum dari sebuah pesantren dan membedakan pendidikan pesantren dengan pendidikan dalam bentuk lain, yaitu kyai, santri, pondok, masjid, dan pengajaran kitab-kitab islam klasik. ${ }^{3}$

Salah satu pesantren yang mempunyai lima elemen diatas adalah pondok pesantren Manbaul Hikam yang berlokasi di Putat Tanggulangin Sidoarjo. Selain mempunyai lima elemen tersebut, pendidikan di pesantren Manbaul Hikam dibagi menjadi tiga macam pendidikan yakni pendidikan formal, pendidikan informal, dan pendidikan nonformal. Yang termasuk pendidikan formal ialah Madrasah Tsanawiyah (Mts) dan Madrasah Aliyah (MA). Sedangkan pendidikan informal ialah Madrasah Diniyah (Madin) dan TPQ. Dan untuk pendidikan nonformal ialah Tahfidzil Qur'an dan Tarekat Qadiriyah.

Di era globalisasi ini, pendidikan agama sangat dibutuhkan sebagai pengendali likaliku kehidupan. Madrasah Diniyah Manba'ul Hikam merupakan madrasah diniyah yang masih memegang teguh tradisi salafiyahnya dengan tidak mengesampingkan modernisasi untuk melangkah kedepan dengan lebih baik. Adapun visi dan misi Madrasah Diniyah Manba'ul Hikam adalah : Beriman, Berilmu, Beriman, dan Bermoral.

Pendidikan yang diberikan dalam Madrasah Diniyah adalah pembelajaran kita-kitab kuning, nahwu, sharaf, serta kitab lainnya. Dan tidak lupa pula adanya praktik merawat jenazah untuk santri kelas 5 ulya dan praktik manasik haji untuk santri kelas 6 ulya, yang mana praktik tersebut merupakan ujian akhir kelulusan selain praktik membaca kitab kuning.

Model pembelajaran yang biasa dipakai untuk melakukan praktik manasik haji ialah belajar bersama atau yang biasa disebut sebagai model pembelajaran learning together. Model pembelajaran ini lebih memudahkan para santri dalam memahami dan melaksanakan manasik haji. Namun ada beberapa santri yang juga belum bisa mengikuti model pembelajaran yang seperti ini, karena di dalam model pembelajaran learning together yang mempunyai ciri khas belajar didalam suatu kelompok dengan berbagai macam pendapat dan olah pikir para santri, maka tidak semua santri ikut andil dalam melakukan model pembelajaran yang seperti ini.

Berdasarkan permasalahn yang dipaparkan diatas, maka peneliti tertarik unuk mengambil judul "Implementasi Model Pembelajaran Learning Together dalam Pemahaman Manasik Haji Santri Kelas 6 Ulya Madrasah Diniyah Manba'ul Hikam Tanggulangin Sidoarjo Tahun Ajaran 2020-2021.

\section{Rumusan Masalah}

Berdasarkan latar belakang diatas, maka permasalahan dalam penelitian ini dapat dirumuskan sebagai berikut :

1. Bagaimana implementasi model pembelajaran learning together dalam pemahaman manasik haji santri kelas 6 ulya Madrasah Diniyah Manba'ul Hikam Tanggulangin Sidoarjo tahun ajaran 2020-2021?

2. Adakah kendala yang ditemukan dalam implementasi model pembelajaran learning together dalam pemahaman manasik haji santri kelas 6 ulya Madrasah Diniyah Manba'ul Hikam Tanggulangin Sidoarjo tahun ajaran 2020-2021 ?

3 Zamakhsyari Dhofier, Tradisi Pesantren, (Jakarta: Pustaka LPE3S, 2011), hlm. 44. 
3. Bagaimana solusi dalam mengatasi kendala implementasi model pembelajaran learning together dalam pemahaman manasik haji santri kelas 6 ulya Madrasah Diniyah Manba'ul Hikam Tanggulangin Sidoarjo tahun ajaran 2020-2021

\section{Tujuan Penelitian}

Tujuan yang ingin dicapai dalam penelitian ini adalah :

1. Untuk mengetahui bagaimana implementasi model pembelajaran learning together dalam pemahaman manasik haji siswa kelas 6 ulya Madrasah Diniyah Tanggulangin Sidoarjo tahun ajaran 2020-2021.

2. Untuk mengetahui kendala apa saja yang ada dalam implementasi model pembelajaran learning together dalam pemahaman manasik haji siswa kelas 6 ulya Madrasah Diniyah Tanggulangin Sidoarjo tahun ajaran 2020-2021.

3. Untuk mengetahui solusi dalam mengatasi kendala yang ada pada implementasi model pembelajaran learning together dalam pemahaman manasik haji siswa kelas 6 ulya Madrasah Diniyah Tanggulangin Sidoarjo tahun ajaran 2020-2021.

\section{Manfaat Hasil Penelitian}

1. Manfaat Teoritis

a. Penelitian ini diharapkan bisa digunakan untuk mengembangkan pemahaman para siswa dalam pelaksanaan manasik haji.

b. Penelitian ini diharapkan bisa menjadi bahan pertimbangan untuk jenis penelitian selanjutnya.

2. Manfaat Praktis

Penelitian ini diharapkan dapat memberi kontribusi praktis yang berguna bagi STAI TARUNA, guru, siswa, sekolah, pembaca dan peneliti sebagai berikut:

a. Manfaat bagi STAI TARUNA

Khusunya prodi PAI, dapat dijadikan sebagai bahan masukan untuk memperbaiki model-model pembelajran yang dilakukan oleh Mahasiswa STAI TARUNA (Prodi PAI) agar menerapkan pembelajaran yang lebih menarik lagi, sehingga kualitas pembelajaran tentang manasik haji yang termasuk dalam mata pelajaran fiqih meningkat.

b. Manfaat bagi guru

Dapat dijadikan evaluasi, khususnya guru yang bertanggung jawab atas proses pelaksanaan manasik haji agar para siswa lebih mudah memahami proses pembelajaran yang dilakukan.

c. Manfaat bagi siswa

Dapat dijadikan pembelajaran manasik haji yang menarik dan menyenangkan dengan adanya model pembelajaran learning together.

d. Manfaat bagi sekolah

Dapat memberikan referensi dalam meningkatkan kualitas pendidikan dan proses belajar mengajar yang dilakukan oleh guru. Serta sekolah dapat memberikan dukungan kepada para guru untuk menciptakan model pembelajaran yang lebih bervariasi lagi.

e. Manfaat bagi pembaca

Sebagai penambah wawasan serta pengalaman yang berhubungan dengan manasik haji. 


\section{f. Manfaat bagi peneliti}

Dapat menambah wawasan dalam mengembangkan dan menerapkan model pembelajaran learning together dalam pemahaman manasik haji.

\section{Metode Penelitian}

\section{Pendekatan dan Jenis Penelitian}

Penelitian ini termasuk jenis penelitian lapangan dan menggunakan pendekatan deksripsi kualitatif yaitu penelitian yang memaparkan pengumpulan yang mengedepankan pengumpulan data atau realitas personal yang berlandasan pada pengungkapan apa-apa yang telah dieksplorasikan atau diungkapkan oleh responden. Data yang dikumpulkan berupa kata-kata tertulis atau lisan dari orang-orang yang diamati.

Metode kualitatif adalah metode penelitian yang berlandaskan pada filsafat postpositivisme, digunakan untuk meneliti pada kondisi objek yang ilmiah, (sebagai lawannya dari eksperimen) dimana peneliti adalah sebagai instrument kunci, pengambilan sampel sumber data dilakukan secara surposive dan snowbad, teknik pengumpulan dengan tringagulasi gabungan, analisis data bersifat induktif/kualitatif, dan hasil penelitian kualitatif lebih menekankan makna dari generalisasi.

Penelitian kualitatif dalam sisi definisi lainnya dikemukakan bahwa hal itu merupakan penelitian yang memanfaatkan wawancara terbuka untuk menelaah dan memahami sikap, pandangan, perasaan, dan perilaku individu atau sekelompok orang.

Penelitian kualitatif ditujukan untuk mendeskripsikan dan menggambarkan fenomena-fenomena yang ada, baik bersifat alamiah maupun rekayasa manusia, yang lebih memperhatikan mengenai karakteristik, kualitas, keterkaitan antar kegiatan.

Jenis penelitian kualitatif menafsirkan dan menguraikan data yang ada bersamaan dengan situasi yang sedang terjadi. Penelitian ini juga mengungkapkan sikap, pertentangan, hubungan serta pandangan yang terjadi pada sebuah lingkup responden.

Penelitian kualitatif menggambarkan kondisi apa adanya, tanpa memberi perlakuan atau manipulasi pada variable yang diteliti. Jenis ini merupakan jenis penelitian dengan proses memperoleh data bersifat apa adanya. Penelitian ini lebih menekankan makna pada hasilnya.

Tujuan peneliti mengambil metode penelitian kualitatif adalah mendeskripisikan tentang model pembelajaran learning together.

\section{Lokasi Penelitian}

Lokasi penelitian ini dilakukan di Madrasah Diniyah Manba'ul Hikam Tanggulangin Sidoarjo. Peneliti memilih lokasi ini, karena di madrasah diniyah ini tidak semua santri paham akan teori manasik haji, bahkan saat praktek manasik haji terkadang masih ada santri yang kurang paham. 
Dalam penelitian ini, yang menjadi obyek penelitian adalah kepala Madrasah Diniyah, guru-guru yang berkecimpung dalam manasik haji, serta para santri kelas 6 Ulya yang sudah melaksanakan manasik haji.

\section{Hasil dan Pembahasan}

\section{Gambaran Umum Objek Penelitian}

\section{Identitas Madrasah Diniyah}

Madrasah Diniyah Manba'ul Hikam merupakan salah satu pendidikan informal yang berada dibawah naungan pondok pesantren Manba'ul Hikam Sidoarjo yang berdiri pada tahun 1982 yang mana Madrasah Diniyah juga berdiri sejak pondok pesantren Manba'ul Hikam diubah namanya dari pondok pesantren Darul Ulum. Madrasah Diniyah ini beralamat di Jalan Putat Utara RT 009 RW 002 Putat Tanggulangin Sidoarjo Jawa Timur.

Adapun tingkatan kelas yang ada di Madrasah Diniyah Manba'ul Hikam, yakni dari kelas 1,2,3 wustho sampai dengan kelas 4,5,6 ulya. Waktu pembelajaran yang ada di Madrasah Diniyah ini dimulai dari jam 07.30-10.00 WIB. ${ }^{4}$

\section{Organisasi Kepengurusan Madrasah Diniyah Manba'ul Hikam}

Susunan pengurus Madrasah Diniyah Manba'ul Hikam periode 2020-2021 adalah sebagai berikut.
a. Kepala Madrasah
: Hj. Ilusia Insyiroh
b. Waka Kurikulum
: Moh. Mursyidin, S.Pd
c. Waka Kesiswaan
: H. Ach. Fuad Syarief
d. Waka SarPras
: H. Ach. Subhan
e. Waka Humas
: M. Qodli, S.Pd
f. TU Administrasi
: Mas Agung Primadani, S.Pd.I
g. Bendahara
: Moch. Makmur, S.H.I
h. Bendahara BOS
: Ach. Dluha, S.Pd
i. Waka TU
: Ibnu Muallim
j. Ketua MGMP
: Hj. Amiroh Aulia Sari, S.Pd
k. Ketua Team Kreatif : Nadya Najma
1. Wali Kelas Takhossush : M. Taufiqurrifqi, M.H.I

\section{Sejarah Berdirinya Madrasah Diniyah Manba'ul Hikam}

Sejarah berdirinya madrasah diniyah ini sangat berkaitan dengan berdirinya Pondok Pesantren Manba'ul Hikam, karena madrasah diniyah merupakan kegiatan inti pendidikan di dalamnya.

Manba' adalah sebuah istilah bahasa Arab yang berarti sumber atau tempat mengalirnya sesuatu. Hikam adalah bentuk kata plural (jamak) dari kata al-hikmah. Secara bahasa kata al-hikmah berarti kebijaksanaan, dengan demikian, kata al-hikam berarti beberapa hikmah atau kebijaksanaan. Kata manba' jika digabungkan dengan kata al-

\footnotetext{
${ }^{4}$ Dokumen Madrasah Diniyah Manba'ul Hikam Tahun 2017
} 
hikam membentuk tarkib idhofi (susunan mudhaf dan mudhaf ilaih) yaitu Manba'ul Hikam yang berarti sumber mengalirnya berbagai hikmah dan kebijaksanaan.

Pesantren Manba'ul Hikam adalah lembaga pendidikan yang dirintis dan didirikan oleh almaghfurlah KH. Khozin Mansur yang berasal dari Mayangan Jogoroto Jombang. Sebelumnya Pesantren Manba'ul Hikam ini bernama Pesantren Darul Ulum. Pada awal tahun 1970-an, Manba'ul Hikam masih berupa majelis ta'lim dan sarana pendidikan rohani (majelis tariqot) bagi kaum muslimin di sekitar wilayah kecamatan Tanggulangin.

Sejak kecil Muhammad Khozin Mansur hidup di lingkungan keluarga yang religius. Pendidikan dan ilmu-ilmu (khususnya ilmu agama) ia peroleh dari orang tuanya $(\mathrm{KH}$. Muhammad Mansur) dan saudara tuanya yaitu Kiai Minhaj. KH. Muhammad Mansur adalah pengasuh Pondok Pesantren Madinatut Ta'lim di Dusun Wonokoyo, Desa Mayangan, Kecamatan Peterongan, Jombang. Dua tokoh di atas adalah orang yang sangat besar pengaruhnya dalam mentransformasikan dasar-dasar agama, aqidah, al-Qur'an, dan akhlaqul karimah kepada Muhammad Khozin Mansur.

Sejak belia, Muhammad Khozin Mansur sudah memiliki semangat yang tinggi dalam menuntut ilmu pengetahuan. Muhammad Khozin Mansur belajar agama di ayah dan saudaranya, beliau juga belajar di Sekolah Rakyat (SR) di desa Parimono, sekitar 5 km arah selatan desa Mayangan. Tamat menuntut ilmu pada jenjang pendidikan dasar (SR) di Parimono, Muhammad Khozin Mansur dipasrahkan ayahnya kepada Hadrotus Syeikh KH. Hasyim Asy'ari untuk bisa menuntut ilmu-ilmu agama di pondok pesantren yang di asuhnya yaitu Pesantren Tebu Ireng Jombang. Bertahun-tahun mondok di Tebu Ireng dimanfaatkan dengan sebaik-baiknya oleh Muhammad Khozin Mansur untuk mengkaji ilmu-ilmu agama seperti ilmu al-Qur'an, nahwu, shorof, dan kitab-kitab hadits Shohih alBukhori yang di susun oleh Abu Abdillah Muhammad ibnu Ismail al-Bukhori dan Shohih Muslim yang disusun oleh Al-Imam Muslim serta kitab-kitab hadits lainnya seperti Sunnah At-Turmudzi, Sunnah Nasa'I, Sunnah Abu Dawud, dan Sunnah Ibnu Majah.

Setelah berguru pada maha gurunya Kiai Jawa, Muhammad Khozin Mansur pindah nyantri ke Rejoso. Muhammad Khozin Mansur langsung di perintah oleh KH. Dahlan, salah satu ulama dan keluarga dekat KH. Romli Tamim, untuk mengajar para santri pesantren Rejoso. Hari- harinya di pesantren Rejoso diprioritaskan oleh Muhammad Khozin Mansur untuk mengajar para santri. Bahkan, KH. Dahlan juga mengatakan bahwa segala hal yang berkaitan dengan pengajaran di madrasah di pesantren Rejoso ini dipasrahkan kepada beliau. Amanat KH. Dahlan tersebut justru menjadi mesin pendorong Muhammad Khozin Mansur untuk semakin haus belajar dan mendalami semua ilmu yang telah dipelajarinya. Tiap malam utamanya pada waktu dini hari, ia tidak pernah berhenti muthola'ah kitab-kitab yang telah dipelajarinya walaupun dalam kegiatan muthola'ah itu harus ia lakukan sendirian.

Beliau kemudian mengakhiri masa lajangnya dengan menikahi Machniyah (seorang putri dari H. Musthofa). Beliau adalah seorang pengusaha tambak yang kaya di desa Putat 
dan cinta sekali kepada orang yang berilmu. Setelah menikah, $\mathrm{KH}$. Khozin beserta istrinya dikaruniai lima orang putri dan berjuang mensyiarkan agama Islam lewat dunia pendidikan dengan:

a. Mendirikan Sekolah Rakyat Islam (SRI) dan Pendidikan Guru Agama (PGA), yang kemudian berkembang menjadi: Yayasan Pendidikan dan Sosial "Al-Islamiyah" Putat Tanggulangin Sidoarjo (YAPISSA: SD, SMP, SMA).

b. Mendirikan Pondok Pesantren "Manba'ul Hikam" Putat Tanggulangin Sidoarjo

1) 1970 : Majelis Ta'lim

2) 1972 :Pondok Pesantren Darul Ulum (Tariqot Mu'tabaroh)

3) 1982 : Pondok Pesantren Manba'ul Hikam

4) 1982 : Madrasah Diniyah Manba'ul Hikam

5) 1993 : Tahfidzil Qur'an

6) 1999 : Madrasah Tsanawiyah Manba'ul Hikam

7) 2002 : Madrasah Aliyah Manba'ul Hikam

8) 2006 : TPQ Manba'ul Hikam Metode Qira'ati

Menempuh proses perkembangan selama 31 tahun, tercatat pada tahun 2016 ini, Manba'ul Hikam telah mempunyai delapan lembaga pendidikan. Delapan unit di atas, dibentuk oleh almaghfurlah KH. Khozin Mansur dan seluruh keluarga dengan niat ikhlas untuk berkhidmat (berpartisipasi) mendidik masyarakat agar menjadi masyarakat yang muslim, berilmu, berketerampilan, dan berakhlaqul karimah.

\section{Visi dan Misi Madrasah Diniyah}

Madrasah Diniyah Manba'ul Hikam merupakan madrasah diniyah yang masih memegang teguh tradisi salafiyahnya dengan tidak mengesampingkan modernisasi untuk melangkah kedepan dengan lebih baik.

a. Visi

Mengantarkan santri menjadi orang yang bermanfaat bagi berbagai aspek kehidupan di lingkungannya, hal ini berdasarkan pada sabda Nabi Muhammad SAW. yang artinya

"Sebaik-baik manusia adalah yang paling bermanfaat bagi sesama manusia" (HR. Muttafaq Alaih)

b. Misi

Membentuk santri yang beriman, berilmu, bermoral, berkarya.

Adapun slogan atau tagline yang dimilki oleh Madrasah Diniyah Manba'ul Hikam yakni sam'an wa tha'atan.

\section{Keadaan Guru Madrasah Diniyah Manba'ul Hikam}

Jumlah guru secara keseluruhan di Madrasah Diniyah Manba'ul Hikam pada tahun ajaran 2020-2021 sebanyak 53 orang tenaga pendidik. Adapun guru laki-laki berjumlah 47 orang, sedangkan guru perempuan berjumlah 6 orang.

Untuk lebih jelas tentang keadaan guru Madrasah Diniyah Manba'ul Hikam dapat dilihat pada tabel berikut : 
Tabel 4.1 Keadaan Guru Madrasah Diniyah Manba'ul Hikam

\begin{tabular}{|c|c|c|c|}
\hline No. & Nama & $\mathrm{L} / \mathrm{P}$ & Tugas Mengajar \\
\hline 1 & H. Abd. Wachid Harun & $\mathrm{L}$ & Ushul Fiqh, Ilmu Tafsir \\
\hline 2 & H. Habiburrahman & $\mathrm{L}$ & Tarikh \\
\hline 3 & Shobari Achmad & $\mathrm{L}$ & Nahwu \\
\hline 4 & Moh. Mursyiddin, S. Pd & $\mathrm{L}$ & Faraidl, Nahwu, Fiqih \\
\hline 5 & Drs. Khusnul Hidayat & $\mathrm{L}$ & I'rob \\
\hline 6 & H. Chabibul Machbub & $\mathrm{L}$ & Ilmu Arudl, Akhlaq, Tauhid \\
\hline 7 & H. Ach. Saichu Adlan & $\mathrm{L}$ & B.Arab, Fiqih, Qawaidul \\
\hline 8 & Imam Hanafi, S. Pd & $\mathrm{L}$ & Akhlaq \\
\hline 9 & H. Ach. Subhan & $\mathrm{L}$ & Fiqih, Akhlak, Qira'atul \\
\hline 10 & H. Moh. Fathoni, M. Pd.I & $\mathrm{L}$ & Tarikh, Qawaidul Fiqih \\
\hline 11 & M. Ali Mashuri, S.Pd & $\mathrm{L}$ & Tarikh \\
\hline 12 & Moch. Khoirul Sholeh & $\mathrm{L}$ & Ilmu Bayan \\
\hline 13 & Moch. Fayakun Syah & $\mathrm{L}$ & Fiqih \\
\hline 14 & Moch. Marsyidi, S.Pd & $\mathrm{L}$ & Nahwu, Shorof \\
\hline 15 & Misbachul Munir, S.Ag & $\mathrm{L}$ & B.Arab, Qawaidul Fiqih \\
\hline 16 & Moch. Qodli, S.Pd.I & $\mathrm{L}$ & Fiqih, Tauhid, Manthiq \\
\hline 17 & Ach. Dluha, S.Pd & $\mathrm{L}$ & Shorof, Tauhid \\
\hline 18 & Abd. Rouf & $\mathrm{L}$ & Fiqih, Shorof \\
\hline 19 & Misbachul Munir & $\mathrm{L}$ & Shorof, Tauhid \\
\hline 20 & Achmad Anas Chayat & $\mathrm{L}$ & Shorof \\
\hline 21 & Imam Fauzi & $\mathrm{L}$ & Shorof, Fiqih \\
\hline 22 & Imam Baihaqi, S.Pd.I & $\mathrm{L}$ & Nahwu, Shorof \\
\hline 23 & Yusni Mas'ud, M.Pd.I & $\mathrm{L}$ & Nahwu, I'rab \\
\hline 24 & H. Agus Arifuddin, M.Pd.I & $\mathrm{L}$ & Ilmu Hisab, Falak 3, Balaghah \\
\hline 25 & Hj. Ilusia Insyiroh & $\mathrm{P}$ & Nahwu \\
\hline 26 & Hj. Amiroh Aulia Sari, S.Pd.I & $\mathrm{P}$ & Bahasa Arab \\
\hline 27 & H. Bahron Nafi' & $\mathrm{L}$ & Akhlaq \\
\hline 28 & Badia'atus Sholihah & $\mathrm{P}$ & Akhlaq \\
\hline 29 & Fahrur Rozi, S.H.I & $\mathrm{L}$ & Falak 3 \\
\hline 30 & Shofiyulloh, S.H.I & $\mathrm{L}$ & Insya', I'rab \\
\hline 31 & Syafi'udin Ahmad & $\mathrm{L}$ & Khot \\
\hline 32 & Ahmad Wahyudi & $\mathrm{L}$ & Shorof, I'rab, Insya' \\
\hline 33 & Fuad Junaedi, S.H.I & $\mathrm{L}$ & Shorof, Insya', I'rab \\
\hline 34 & Nahwan Mas'udi, S.H.I & $\mathrm{L}$ & Qawa'idul I'lal \\
\hline 35 & Moh. Ma'mur, S.H.I & $\mathrm{L}$ & Nahwu, Akhlaq \\
\hline 36 & M. Sirojul Munir, S.Kom & $\mathrm{L}$ & Falak 1 \\
\hline
\end{tabular}




\begin{tabular}{|l|l|l|l|}
\hline 37 & H. Ach. Fuad Syarif & L & Tauhid, Akhlaq, Fiqih \\
\hline 38 & Amar Sukri, S.Pd.I & L & Khot \\
\hline 39 & Yatimul Asma' & L & Tauhid, Tajwid, Nahwu \\
\hline 40 & Mas Agung Primadani & L & Nahwu, Shorof, Akhlaq \\
\hline 41 & Farichul Jinan, S.Pd.I & L & Qawa'idul I'lal, Tauhid \\
\hline 42 & H. Riza Rifqy, S.Pd.I & L & Fiqih \\
\hline 43 & Eko Priyo Utomo, S.Pd.I & L & Insya' \\
\hline 44 & Ach. Zainal Musthofa & L & Fiqih \\
\hline 45 & Ibnu Mu'allim & L & Tauhid. Imla', Qiro'atul Kitab \\
\hline 46 & Ach. Asrojuddinul Asyhari & L & Imla', Qiro'atul Kitab \\
\hline 47 & Moch. Taufiqur Rifqi, M.H.I & L & Insya', Qiro'atul Kitab \\
\hline 48 & Nadia Najma & P & Nahwu, Imla', Qiro'atul Kitab \\
\hline 49 & Naziha Evaliza, S.Pd.I & P & Bahasa Arab \\
\hline 50 & Moch. Rifa'i & L & Tauhid, Qiro'atul Kitab \\
\hline 51 & Devi Agusdina & P & Imla' \\
\hline 52 & Khoirul Anam, M.Pd.I & L & Falak \\
\hline 53 & H.Moch. Sa'ad Yumnan & L & Bahasa Arab \\
\hline
\end{tabular}

*dokumen sekolah madrasah diniyah th 2021

\section{Sarana dan Prasarana}

Fasilitas dan sarana dalam pembelajaran di Madrasah Diniyah Manba'ul Hikam masih klasikal, akan tetapi ada sarana modern yang menunjangnya. Sarana modern ini digunakan sebagai sarana santri untuk membantu mengerjakan tugas dari Madrasah Diniyah Manba'ul Hikam seperti ruang komputer dan perpustakaan.

Kelas yang digunakan terbentuk seperti kelas-kelas yang ada di sekolah formal pada umumnya, dengan menempati ruang-ruang yang ada di gedung madrasah. Fasilitas dan sarana pembelajaran di Madrasah Diniyah Manba'ul Hikam adalah sebagai berikut :

Tabel4.2 Sarana dan Prasarana Madrasah Diniyah Manba'ul Hikam

\begin{tabular}{|c|c|c|}
\hline No. & Sarana & Jumlah \\
\hline 1 & Asrama Santri & 2 \\
\hline 2 & Gedung Madrasah Diniyah & 1 \\
\hline 3 & Ruang Kelas Madin & 34 \\
\hline 4 & Kantor & 1 \\
\hline 5 & Masjid & 1 \\
\hline 6 & Musholla & 1 \\
\hline 7 & Perpustakaan & 1 \\
\hline 8 & Laboratorium Komputer & 1 \\
\hline 9 & Laboratorium Bahasa & 1 \\
\hline
\end{tabular}


IMPLEMENTASI MODEL PEMBELAJARAN LEARNING TOGETHER DALAM PEMAHAMAN MANASIK HAJI SANTRI MADRASAH DINIYAH MANBA'UL HIKAM - Nasiri, Siti Hafshah Solehatunnisa

\begin{tabular}{|l|c|l|}
\hline 10 & Koperasi Pesantren & 1 \\
\hline 11 & Pos Kesehatan Pesantren & 1 \\
\hline 12 & Kantin & 1 \\
\hline 13 & Lapangan Olahraga & 1 \\
\hline
\end{tabular}

\section{Data Hasil Penelitian}

Implementasi Model Pembelajaran Learning Together dalam Pemahaman Manasik Haji

Implementasi adalah kegiatan yang dilakukan dengan perencanaan dan mengacu kepada aturan tertentu untuk mencapai tujuan suatau kegiatan.Model pembelajaran learning together merupakan model pembelajaran yang efektif digunakan dalam pemahaman manasik haji. Pelaksanaan model pembelajaran ini dengan cara berkelompok dan membutuhkan kerja sama antar anggota.

Beberapa ahli berpendapat bahwa bahwa model ini unggul dalam memahami konsep-konsep yang sulit. Pembelajaran learning together ini mempunyai gagasan mengenai tanggung jawab pribadi dan sikap menghormati sesama. Guru berperan sebagai fasilitator dalam memberikan materi, sedangkan para siswa bertanggung jawab atas mereka sendiri dan berusaha menemukan informasi untuk menjawab pertanyaan yang diberikan oleh guru.

Manfaat model pembelajaran learning together dalam pemahaman manasik haji bagi guru adalah memudahkan untuk melakulan analisis terhadap perilaku santri secara personal maupun kelompok dalam waktu yang relatif singkat. Sedangkan bagi santri adalah memudahkan nya untuk memahami materi pembelajaran serta rasa tanggung jawab terhadap diri nya sendiri maupun kelompoknya.

Dari hasil wawancara dengan Kepala Madrasah Diniyah Manba'ul Hikam, Hj. Ilusia Insyiroh mengatakan bahwa model pembelajaran learning together ini telah digunakan dalam pemahaman manasik haji santri kelas 6 ulya dengan dibagi menjadi 3 sesi.

Sesi yang pertama ialah pembekalan teori tentang manasik haji. 133 santri putra dan putri kelas 6 ulya dikumpulkan menjadi satu dan dibagi menjadi beberpa kelompok, santri putri sendiri maupun sebaliknya santri putra. Adanya teori tentang pemahaman manasik haji ini bertujuan untuk memudahkan para santri dalam melaksanakan ujian praktek manasik haji yang merupakan persyaratan dari kelulusan akhir kelas. Teori yang diberikan kepada santri kelas 6 ulya adalah tentang bagaimana pelaksanaan manasik haji yang urut dan benar, serta do'a-do'a yang harus diucapkan ketika pelaksanaan manasik haji.

Sesi yang kedua ialah penerapan di lapangan. Sesi ini bisa dibilang seperti gladi bersih. Pada tahap sesi kedua ini para santri kelas 6 ulya sudah bisa melakukan apa saja 
yang telah disampaikan para guru pada saat pembekalan dan sudah difasilitasi miniatur ka'bah dan miniatur lainnya dari madrasah diniyah sendiri. Disini sudah menjadi aturan dalam model pembelajaran learning together yang mana setelah guru menjelaskan suatu materi pembelajaran dan selanjutnya para santri yang sudah memiliki kelompok masingmasing untuk melakukan tugasnya.

Sesi yang ketiga ialah ujian praktek manasik haji yang merupakan syarat kelulusan madrasah diniyah kelas akhir. Tugas guru hanya menilai kinerja dan kekompakan setiap kelompok yang sebelumnya sudah diberi pemahaman manasik haji. Pada tahap ini tugas santri yang lebih dominan menonjol, karena mereka harus bekerja sama dengan tim nya masing-masing, serta mempresentasikan tugasnya dengan cara melakukan praktek manasik haji dengan baik dan benar sesuai materi yang telah diberikan oleh para guru. ${ }^{5}$ Saat melaksanakan ujian praktek manasik haji, para santri masih tetap membawa buku panduan manasik haji, karena menurut ustadzah Amiroh Aulia Sari selaku guru pembimbing pemahaman manasik haji mengatakan bahwa mereka (santri kelas 6 ulya) tidak dituntut untuk hafal, yang terpenting mereka bisa memahami nya, bagaimana cara berdo'a yang benar. ${ }^{6}$

Dari hasil wawancara diatas, maka pendapat peneliti mengenai implementasi model pembelajaran laerning together dalam pemahaman manasik haji santri kelas 6 ulya ini sudah diterapkan dengan baik dan benar. Pembekalan materi dan teori yang diberikan oleh guru, kemudian dilanjutkan dengan membuat beberapa kelompok yang mempunyai tugas dan tujuan yang sama.

Para santri menerima pembekalan teori yang diberikan, dan menerapkan nya disaat ujian praktek manasik haji.

\section{Kendala Implementasi Model Pembelajaran Learning Together dalam Pemahaman Manasik Haji.}

Dalam pengertian fiqih, manasik merupakan rukun haji yang terdiri dari berniat, berpakaian ihram, thawaf, sa'i lalu wuquf di Padang Arafah, mabit di Muzadalifah dan melontar jumrah dan rangkaian manasik haji lainnya.Manasik haji ini bertujuan untuk melatih diri agar mengetahui dan terbiasa dengan hal-hal yang harus dilakukan selama menunaikan ibadah di sana. Serta sebagai penyesuaian dengan segala hal yang akan kita gunakan selama beribadah haji shingga saat memunaikan ibadah haji tidak lagi merasa kebingungan atas tata cara pelaksanannya.

Dengan memahami rangkaian dan tata cara ibadah haji, maka kecil kemungkinan ibadah haji yang dilakukan akan rusak atau batal, sehingga kita tidak perlu

${ }^{5}$ Hj. Ilusia Inyisroh, Wawancara, Sidoarjo, Madrasah Diniyah Manba'ul Hikam, 03 Juli 2021. 2021.

${ }^{6}$ Hj. Amiroh Aulia Sari, S.Pd., Wawancara, Sidoarjo, Madrasah Diniyah Manba'ul Hikam, 20 Agustus 
mengulanginya di musim haji, namun biasanya seorang pembimbing hanya memberikan pemahaman global kepada para calon jama'ah.

Dalam pelakasanaan pemahaman manasik haji pastinya terdapat satu atau dua kendala yang ditemukan. Dari hasil wawancara dengnan Kepala Madrasah Diniyah Manba'ul Hikam, Hj. Ilusia Insyiroh mengatakan bahwa tidak ditemukan kendala dalam pemahaman manasik haji santri kelas 6 ulya. Hal ini sama seperti yang dikatakan oleh $\mathrm{Hj}$ Amiroh Aulia Sari selaku guru pembimbing manasik haji bahwa semua berjalan lancar dari awal pembekalan teori sampai pada ujian praktek manasik haji. Para santri terlihat memahami pelaksanaan manasik haji, semua santri terlihat sudah hafal akan do'a-do'a manasik haji dan membaca dengan lantang saat ujian praktek manask haji.

Namun berbeda dengan pendapat salah satu santri kelas 6 Ulya, Umi Faridatur Rofiqoh yang telah mengikuti dan melaksanakan pemahaman manasik haji. Dia mengatakan bahwa saat sesi pembekalan pemahaman manasik haji, ia kurang bisa mengikuti dan memahami, namun ketika praktek langsung, dengan adanya bimbingan dari para guru, maka ia tidak terlalu bingung untuk melaksanakan manasik haji tersebut.

Dari hasil wawancara diatas, maka peneliti menyimpulkan bahwa kendala yang ditemukan tidak begitu kompleks atau rumit, karena bisa saja kendala ini ditemukan penyebabnya dari santri itu sendiri ataupun faktor lain. Saat beberapa santri tidak dapat memahami teori atau pembekalan yang diberikan pada manasik haji, setidaknya pada saat praktek ujian manasik haji berlangsung, mereka semua dapat mengikuti dengan baik dan melaksanakannya sesuai dengan apa yang diberi saat proses pemahaman manasik haji.

\section{Solusi untuk Mengatasi Kendala dalam Implementasi Model Pembelajaran Learning Together.}

Solusi merupakan jalan keluar atau jawaban dari suatu masalah. Solusi adalah cara atau jalan yang digunakan untuk memecahkan dan menyelesaikan masalah tanpa adanya tekanan. Maksud adanya tekanan adalah adanya objektivitas dalam menentukan solusi dimana orang yang mencari solusi tidak memaksakan pendapat pribadinya dan berpedoman pada kaidah atau aturan yang ada. Jika tidak demikian maka solusi yang didapat akan sangat subjektif sehingga dikhawatirkn bukan merupakan solusi terbaik. Untuk mendapatkan solusi atas suatu permasalahan ada beberapa tahapan yang dilalui. Pertama kita perlu mengenali apa sebenarnya masalah yang terjadi. Kemudian mencari fakta atau bukti mengenai permasalahan tersebut. Setelah itu ditelaah apa yang melatarbelakangi munculnya masalah tersebut. Setelah jelas masalah beserta latar belakangnya, barulah kita dapat mempertimbangkan berbagai kemungkinan solusi yang dapat digunakan untuk memecahkan masalah tersebut. 
Dari kendala yang ditemukan, maka menurut peneliti solusinya ialah para santri harus benar-benar memperhatikan pemahaman manasik haji dengan seksama agar pelaksanaan manasik haji bisa berjalan dengan lancar. Jika para pelaku penerapan model pembelajaran learning together yaitu santri dan guru bisa memahami cara kerja model pembelajaran tersebut, maka penulis yakin akan sedikitnya kendala yang ditemukan.

\section{Kesimpulan}

Bahwa dengan megancu pada rumusan masalah tersebut menjadi pokok pembahasan dan hasil yang terkumpul dapat diambil kesimpulan sebagai berikut :

1. Implementasi model pembelajaran learning together dalam pemahaman manasik haji santri kelas 6 ulya madrasah diniyah manba'ul hikam sudah efektif dan diterapkan dengan baik dan benar. Selain mendapatkan ilmu, mereka juga dapat membangun rasa tanggung jawab terhadap diri mereka sendiri maupun sesama anggotanya melalui model pembelajaran learning together.

2. Dari 133 santri yang mengikuti pemahaman manasik haji, saya ambil sampel sebanyak 13 santri, dan dari 13 santri tersebut hanya beberapa yang menemukan kendala saat pelaksanaan pemahaman manasik haji di sesi pembekalan teori yang diberikan oleh para guru.

3. Solusi untuk mengatasi kendala yang ditemukan ialah, sebaiknya para santri harus benarbenar memperhatikan pemahaman manasik haji dengan seksama agar pelaksanaan manasik haji bisa berjalan dengan lancar.

\section{Saran}

Berdasarkan hasil penelitian ini, maka dengan segala kerendahan hati penulis sampaikan saran-saran sebagai berikut :

1. Bagi guru pembimbing manasik haji

a. Memberikan dukungan dan dorongan agar suasana belajar dengan menggunakan model pembelajaran learning together lebih kondusif, sehingga santri akan lebih mudah menerima materi yang disampaikan dalam proses pemahaman manasik haji.

b. Selalu memberikan motivasi belajar terhadap santri untuk selalu belajar dengan giat dan rajin, serta membina hubungan baik dengan para santri agar guru bisa memahami perbedaan kemampuan tiap-tiap siswa.

2. Bagi santri kelas 6 Ulya

a. Hendaknya pada saat pembekalan teori manasik haji, para santri menyimak dengan baik agar pada saat pelaksanaan manasik haji bisa berjalan dengan lancar.

b. Hendaknya para santri bisa selalu bekerja sama dalam kelompok mereka untuk mencapai tujuan pembelajaran yang diinginkan

\section{Daftar Pustaka}


Bagir, Muhammad. 2016, Panduan Lengkap Ibadah menurut Al-Qur'an,Al-Sunnah, dan menurut Pendapat Para Ulama'. (Jakarta Selatan: Noura).

Daradjat, Zakiyah. 1996, Ilmu Jiwa Agama. (Jakarta: Bulan Bintang).

Dhofier, Zamakhsyari. 2011, Tradisi Pesantren (Jakarta: Pustaka LPE3S).

Dokumen Madrasah Diniyah Manba'ul Hikam 2017.

Ismail Nurdin, Sri Hartati. 2019, Metodologi Penelitian Sosial (Surabaya: Media Sahabat Cendekia).

Fatoni, Abdurrahman. 2011, Metodologi Penelitian dan Teknik Penyusunan Skripsi. (Jakarta: Rineka Cipta).

Hidayanto, Dwi Nugroho. 2020, Pengantar Ilmu Pendidikan Teoritis Sistematis untuk Guru dan Calon Guru. (Depok: PT RajaGrafindoPersada).

Isjoni. 2011, Cooperative Learning: Mengembangkan Kemampuan Belajar Berkelompok. (Bandung: Alfabeta).

Nasution, S. 1999, Metode Penelitian Naturalistik Kuantitatif. (Bandung: Tarsito).

Octavia, Shilpy A. 2020, Model-Model Pembelajaran. (Sleman: Deepublish).

R.E, Slavin. 2005, Cooperaative Learning. (Bandung: Nusa Media).

Rohman, Arif. 2009, Memahami Pendidikan dan Ilmu Pendidikan. (Yogyakarta: LaksBang Mediatama Yogyakarta).

S. Amri, lif K.A. 2010, Proses Pembelajaran Kreatif dan Inovatif dalam Kelas. (Jakarta: Prestasi Pustaka).

Subroto, Hadi Subino. 1999, Pokok-Pokok Pengumpulan Data, Analisis Data, Penafsiran Data dan Rekomendasi dalam Penelitian Kualitatif. (Bandung: IKIP).

Sugiyono. 1998, Metodologi Penelitian Administrasi. (Bandung: CV Alfabeta).

Sukmadinata, Syaodih. 2012, Metode Penelitian Pendidikan. (Bandung: PT Remaja Rosdakarya).

Suprijono, Agus. 2009, Cooperative Learning: Teori dan Aplikasi PAIKEM. (Yogyakarta: Pustaka Pelajar). 